\title{
Dosimetric Comparison between Conventional 2D and 3D Conformal Radiotherapy in the Treatment of Intact Breast Cancer
}

\author{
Amr Amin 1*, Ehab El-Kest', Mohammed Mahmoud1, Arafa Abd El-Hafez², \\ Abdul-Hamed El-Kateb ${ }^{3}$, Mohamed El-Nagdy ${ }^{3}$, Aida Tolba ${ }^{3}$, Eman Hemeda ${ }^{3}$, \\ Mohamed Abdelmajeed 4 \\ ${ }^{1}$ Radiation Oncology and Nuclear Medicine Department, National Cancer Institute (NCI), Cairo University, Giza, Egypt \\ ${ }^{2}$ National Institute for standards (NIS), Cairo, Egypt \\ ${ }^{3}$ Physics Department, Faculty of Science, Helwan University, Helwan, Egypt \\ ${ }^{4}$ Physics Unit, Radiation Oncology and Nuclear Medicine Department, NCI, Cairo University, Giza, Egypt \\ Email: *amr.amin@nci.cu.edu.eg
}

How to cite this paper: Amin, A., El-Kest, E., Mahmoud, M., El-Hafez, A.A., El-Kateb, A.-H., El-Nagdy, M., Tolba, A., Hemeda, E. and Abdelmajeed, M. (2017) Dosimetric Comparison between Conventional 2D and 3D Conformal Radiotherapy in the Treatment of Intact Breast Cancer. Journal of Cancer Therapy, 8, 663-671.

https://doi.org/10.4236/jct.2017.87057

Received: December 27, 2016

Accepted: July 17, 2017

Published: July 20, 2017

Copyright $\odot 2017$ by authors and Scientific Research Publishing Inc. This work is licensed under the Creative Commons Attribution International License (CC BY 4.0).

http://creativecommons.org/licenses/by/4.0/

\begin{abstract}
Background: Radiotherapy (RT) techniques after Conservative Breast Surgery (CBS) vary. Three Dimension (3D) planning allows for better plan optimization compared to 2 Dimension (2D) plans and also allowing for creating Dose Volume Histograms (DVHs) for both Planning Target Volume (PTV) and Organs at Risk (OAR). Patients and Methods: Twenty consecutive patients with CBS planned for whole breast and supraclavicular (SCV) RT at the National Cancer Institute (NCI), Egypt between January and June 2016 were included in this study. All patients were planned clinically in 2D fashion with no more than $2 \mathrm{~cm}$ of ipsilateral lung allowed in the tangential fields "Limited 2D" (Limit-2D) then Target and OAR volumes were drawn according to the Radiation Therapy Oncology Group (RTOG) guidelines and 3D plans and a central slice PTV-based 2D plan, "Modified 2D" (Mod-2D), were performed in the same Computerized Tomography (CT) slices for each patient. Mono-Iso-Centeric technique (MIT) was used in 3D plans. DVH parameters were used to compare the three plans. Results. In 3D plans, compared to Limit-2D, coverage improved for the intact breast (V95\% $=95 \%$ versus (Vs) $69 \%$, $p=0.036)$ and SCVPTV (V90\% $=90 \%$ Vs $65 \%, p=0.01)$. The breast and SCV V 107\%, V112\% and Dmax were better with 3D plan however not statistical significant (NS). Junctional hot spots were $120 \%$ and $107 \%$ in the Limit-2D and 3D plans respectively $(p=0.04)$. The dose to the heart, mean (333 Vs 491 cGy), V10 (5\% Vs 10\%) and V20 (3\% Vs 7\%), Ipsilateral lung V20 (19\% Vs $26 \%$ ), and contra lateral breast D-max (205 Vs 462 cGy) were higher in 3D plans however NS, and the dose to the cord was the same. Comparison be-
\end{abstract}


tween 3D and Mod-2D showed better OAR sparing with 3D with mean heart dose (491 cGy Vs 782 cGy, $p=0.025)$ and Ipsilateral lung V20 (26\% Vs 32\%, $p$ $=0.07 \%$ with statistically comparable target coverage. Conclusion: This study demonstrated that application of 3D plan using MIT improves coverage of breast and SCVPTVs with minimizing hot spot at the junctional area if compared with Limit-2D plans with comparable dose to OAR. When compared with Mod-2D plans, 3D plans not only had better target coverage but also better sparing of OAR, the latter was statistically significant.

\section{Keywords}

Mono-Iso-Centeric Technique, Breast Contouring, Breast Conserving Radiotherapy, Dose Volume Histogram (DVH)

\section{Introduction}

Breast cancer is the most common cause of cancer death among women worldwide. In Egypt, breast cancer is the most common cancer among women, representing $17.5 \%$ of total cancer cases (34.3\% in Women and $0.5 \%$ in men) among the National Cancer Institute (NCI) series of 9808 patients during the year 2001, 2003 and 2004, Nadia Mokhtar et al., [1]. After CBS, RT of the breast is performed in most RT centers by using two simple tangential beams. This can be done by using either $2 \mathrm{D}$ or $3 \mathrm{D}$ treatment planning. In case of $2 \mathrm{D}$ treatment planning, the breast is treated by using two tangential parallel opposed fields and one anterior field to treat SCV lymph nodes if needed. The borders of the two tangential beams are determined clinically and the breast is manually contoured in the single axial slice where calculation is done, and SCV lymph nodes are calculated at depth $3 \mathrm{~cm}$, Chika N. Madu et al., [2].

But in case of 3D treatment planning, full CT slices are used to treat both breast and SCV lymph nodes. The use of Multi-Leaf Collimator (MLC) and fields segments allows for better plan optimization. Usage of full CT slices allows for 3D evaluation of dose distribution, minimum, maximum dose and dose to OAR using DVH.

The use of 3D conformal radiotherapy and Intensity Modulated Radiation Therapy (IMRT) in breast cancer was associated with improved acute toxicity and cosmesis [3] [4], in addition to better target coverage DVH parameters [5], however; in case of IMRT, this was associated with higher dose to contra lateral OAR with the known risk of secondary malignancy [6].

With the higher patient-machine ratio and the limited availability of MLCequipped treatment machines in Egypt and most developing countries, even with the use of hypo-fractionated breast RT schedules, every effort should be made to settle on a safe and simpler RT technique.

The aim of this study was to compare dosimetrically between 3D treatment planning using MIT and 2 methods of 2D treatment planning for patients with breast cancer that underwent conservative surgery with respect to PTV coverage 
of the breast and the SCV lymph node, hot spot in the junctional area and dose to OAR.

\section{Patients and Methods}

\subsection{Patients Selection}

Twenty consecutive patients with CBS, in whom whole breast and SCV field irradiation were indicated and were treated at NCI Egypt between January and June 2016, were included in this study. Ten of them had right breast cancer and the other ten patients had left breast cancer.

\subsection{RT Procedures}

All patients were planned clinically using anatomical and bony land marks. Radio-opaque wire ring was placed around the breast to define the breast borders. Patient underwent CT scanning with $25 \mathrm{~mm}$ slice thickness. Target (breast and SCV lymph nodes) and OAR (i.e. heart in case of left sided breast, ipsilateral lung, contra-lateral breast and spinal cord) volumes were delineated according to RTOG guidelines [7]. Treatment planning was done on Precise Treatment Planning System.

\subsection{Two Dimension Plans}

\subsubsection{Limited 2D (Limit-2D) Plan}

Borders of the two tangential parallel opposed beams were defined clinically. The superior border covers as much breast tissue as possible and lies at the lower border of medial end of clavicle. The inferior border lies $2 \mathrm{~cm}$ below the inframammary fold, the medial border is usually in the midline, and the lateral border is in the mid-axillary line, Helen McNair et al., [8]. The posterior borders of the tangential (Tang) fields are aligned to each other and allowed to include not more than $2 \mathrm{~cm}$ of the ipsilateral lung (an institutional method that was frequently used to decrease lung toxicity). This plan was considered limited 2D plan.

\subsubsection{Modified 2D (Mod-2D) Plan}

Re-planning was done in which the 2 tang fields covered the central slice PTV properly provided no crossing of middle line and regardless of how much of the ipsilateral lung was included.

2D Plan Calculations Were Performed in the Central CT-Slice. Wedges were used to improve tissue dose homogeneity and all patients were treated with 6-MV photon beam except in one patient $15 \mathrm{MV}$ photon beam was used.

\subsubsection{SCV lymph Node Field}

For SCV Lymph Node Field, Borders Were Defined Anatomically. The superior border has extended to the thyrocricoid membrane, inferior border has extended to the inferior aspect of the clavicular head matching with tangential field, medial border has extended to the midline, and lateral border has extended to the humeral head [2]. Calculation was done in the central CT-slice at depth $3 \mathrm{~cm}$ using single anterior field at SSD $100 \mathrm{~cm}$ with energy equal $6 \mathrm{MV}$ and gantry an- 
gle equal 10 degree to avoid the spinal cord.

\subsection{Three Dimension Conformal Planning}

In the 3D treatment planning Clinical Target Volume (CTV) and PTV of the breast and SCV lymph nodes were delineated according to RTOG guidelines [7]. MIT was applied to avoid the divergence between tangential beams of breast and the SCV field(s). In this technique the center of all beams was placed at the junction between the PTV of the breast and the PTV of SCV, Svensson GK et al., [9]. The suitable energy, $6 \mathrm{MV}$ or $15 \mathrm{MV}$ was used in these beams. The gantry angles were determined using the Beam's Eye View (BEV). MLC was used to conform the prescribed dose around the PTVs with a margin of $0.7 \mathrm{~cm}$ to avoid the penumbra. Breast field segments were used instead of wedges for plan optimization. In PTV SCV, posterior fields were allowed. The planning was performed based on the 3D Algorithm using Precise-TPS.

\subsection{Prescribed Dose and Plan Evaluation}

A dose of 4005 cGy in 15 fractions over 3 weeks was prescribed. In all techniques DVHs were used to determine V95\% (PTV receiving 95\% of prescribed dose), V90\%, V107\%, V112\%, maximum dose (D-max), and hot spots according to International Commission on Radiation Unit and Measurements (ICRU 50). [10], heart mean dose, V10 (volume of the heart receiving $10 \mathrm{~Gy}$ ) and V20 in case of left sided breast, the volume of Ipsilateral lung receiving $20 \mathrm{~Gy}$ (V20), contra-lateral breast D-max and spinal cord D-max were derived and compared according to RTOG 1005 guidelines [11].

\subsection{Statistical Analysis}

SPSS version 22.0 software (Chicago, IL, USA) was used. The DVH parameters of the cumulative dose plans were compared with analysis of the mean values with the paired-samples t-test. All tests were two-tailed, and differences were considered statistically significant at $p \leq 0.05$.

\section{Results}

\subsection{Limit-2D and 3D Plan Comparison}

The Limit-2D plan, where post borders of the 2 tangential fields were set to include not more than $2 \mathrm{~cm}$ of the ipsilateral lung at the central slice, was compared to 3D plan. The latter used MIT.

The mean V95\%, V107\%, V112\%, and D-max for the breast and mean V90\%, V107\%, V112\%, and D-max for the SCV were better with 3D plans compared to Limit-2D plans and was statistically significant for V95\% breast and V90\% SCV (p 0.036 and 0.01 respectively) (Table 1 ). The Limit-2D plans had lower dose to OAR however without statistical significance (Table 1). Hot spot at the junction between the breast and SCV field in Limit-2D plans had a mean dose of $120 \%$ compared to $107 \%$ in 3D plans which was statistically significant (Table 1). 
Table 1. The dosimetric comparison between limit-2D* and $3 \mathrm{D}^{\star *}$ plans.

\begin{tabular}{|c|c|c|c|c|}
\hline & Parameter & $\begin{array}{l}\text { Limit-2D Plan } \\
\quad \text { Mean } \\
\text { (Std. Deviation) }\end{array}$ & $\begin{array}{c}\text { 3D Plan } \\
\text { Mean } \\
\text { (Std. Deviation) }\end{array}$ & $P$ Value \\
\hline \multirow{5}{*}{$\begin{array}{c}\text { Breast } \\
\text { PTV }^{* * *}\end{array}$} & V95\% & $69 \%(20 \%)$ & $95 \%(3 \%)$ & 0.036 \\
\hline & V107\% & $8.2 \%(6 \%)$ & $2.8 \%(2.5 \%)$ & 0.12 \\
\hline & V112\% & $0.5 \%(0.5 \%)$ & $0 \%$ & 0.55 \\
\hline & $D-\max$ & $124 \%(7 \%)$ & $111 \%(1.7 \%)$ & 0.08 \\
\hline & V90\% & $65 \%(18 \%)$ & $90 \%(4 \%)$ & 0.01 \\
\hline \multirow{3}{*}{$\begin{array}{c}\text { Supraclavicular } \\
\text { PTV }\end{array}$} & V107\% & $10 \%(7 \%)$ & $4(2 \%)$ & 0.15 \\
\hline & V112\% & $3 \%(2 \%)$ & $1 \%(1 \%)$ & 0.12 \\
\hline & D-max & $123 \%(8 \%)$ & $113 \%(4 \%)$ & 0.11 \\
\hline $\begin{array}{l}\text { Junctional Hot } \\
\text { Spot }\end{array}$ & & $120 \%(9 \%)$ & $107 \%(4 \%)$ & 0.04 \\
\hline \multirow{3}{*}{$\begin{array}{c}\text { Heart in Left } \\
\text { Side Breast (10 } \\
\text { Patients) }\end{array}$} & Mean & 333cGy (190 cGy) & 491cGy (110 cGy) & 0.14 \\
\hline & V10 & $5 \%(4 \%)$ & $10 \%(7 \%)$ & 0.13 \\
\hline & V20 & $3 \%(3 \%)$ & $7 \%(5 \%)$ & 0.14 \\
\hline Ipsilateral Lung & V20 & $19 \%(8 \%)$ & $26 \%(6 \%)$ & 0.15 \\
\hline $\begin{array}{c}\text { Contra-Lat } \\
\text { Breast }\end{array}$ & $D-\max$ & 205 cGy (137 cGy) & 462 cGy (144 cGy) & 0.25 \\
\hline Spinal Cord & D-max & 2457 cGy & 2318 cGy & 0.52 \\
\hline
\end{tabular}

${ }^{*}$ Limit-2D where post border was set to include not more than $2 \mathrm{~cm}$ of ipsilateral lung at central slice. ${ }^{* * 3 \mathrm{D}}$

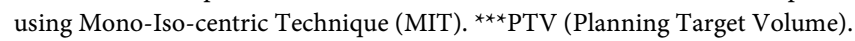

\subsection{Comparison between Mod-2D Plan and 3D Plan}

In the Mod-2D plan the 2 tang fields covered the central slice breast PTV properly regardless of how much Ipsilateral lung was included. This improved breast PTV V95\% however on the expense of less sparing of OAR. The mean heart dose was statistically significantly lower in 3D plan compared to the Mod-2D plan. Also there was a trend towards significance in favor of 3D plan regarding breast D-max, heart V10 and Ipsilateral lung V20 (Table 2). SCV field and junctional hot spot were the same difference as with Limit-2D plan.

\section{Discussion}

For decades, patients with breast cancer received post operative RT using $2 \mathrm{D}$ technique. This technique didn't allow the radiation oncologist and physicist to know dose to OAR or to the PTV above and below the central slice and dose variation across junction area between breast and SCV fields. This study aims at evaluating two $2 \mathrm{D}$ techniques and to compare it to $3 \mathrm{D}$ planning with the use of MIT.

\subsection{Target Coverage}

In case of the $3 \mathrm{D}$ treatment planning, breast V95\% was $95 \%( \pm 3 \%)$ compared to 
Table 2. The comparison between Mod-2D* and $3 \mathrm{D}^{\star *}$ plans.

\begin{tabular}{|c|c|c|c|c|}
\hline & Parameter & $\begin{array}{c}\text { Mod-2D Plan } \\
\text { Mean } \\
\text { (Std. Deviation) }\end{array}$ & $\begin{array}{c}\text { 3D Plan } \\
\text { Mean } \\
\text { (Std. Deviation) }\end{array}$ & P Value \\
\hline \multirow{4}{*}{$\begin{array}{c}\text { Breast } \\
\text { PTV }^{\star * *}\end{array}$} & V95\% & $84 \%(10 \%)$ & $95 \%(3 \%)$ & 0.29 \\
\hline & V107\% & $7.3 \%(4 \%)$ & $2.8 \%(2.5 \%)$ & 0.11 \\
\hline & V112\% & $0.9 \%(0.9 \%)$ & $0 \%$ & 0.54 \\
\hline & $D-\max$ & $115 \%(3 \%)$ & $111 \%(1.7 \%)$ & 0.06 \\
\hline Heart in Left & Mean & 782 cGy (100 cGy) & 491 cGy (110 cGy) & 0.025 \\
\hline Side Breast (10 & V10 & $25 \%(7 \%)$ & $10 \%(7 \%)$ & 0.07 \\
\hline Patients) & $\mathrm{V} 20$ & $8 \%(5 \%)$ & $7 \%(5 \%)$ & 0.2 \\
\hline $\begin{array}{l}\text { Ipsilateral } \\
\text { Lung }\end{array}$ & V20 & $32 \%(4 \%)$ & $26 \%(6 \%)$ & 0.07 \\
\hline $\begin{array}{c}\text { Contra-Lat } \\
\text { Breast }\end{array}$ & $D-\max$ & 637 cGy (296) & 462 cGy (144 cGy) & 0.54 \\
\hline Spinal cord & $D-\max$ & 979 cGy & $1218 \mathrm{cGy}$ & 0.49 \\
\hline
\end{tabular}

${ }^{*}$ The Mod-2D plan was modified so that the 2 tang fields covered the central slice breast PTV. ${ }^{*} 3 \mathrm{D}$ using Mono-Iso-centric Technique (MIT). ${ }^{* * * P T V ~(P l a n n i n g ~ T a r g e t ~ V o l u m e) . ~}$

an average value of $69 \%( \pm 20 \%)$ in Limit-2D plans. This better coverage was statistically significant $(p=0.036)$. Limiting post border of tangential fields to include not more than $2 \mathrm{~cm}$ of ipsilateral lung in these Limit-2D plans led to missing medial and lateral parts of the breast PTV and hence poor coverage. The 3D plans were also associated with better breast V107\%, V112\%, and D-max however NS.

The SCV V90\% was $90 \%( \pm 4 \%)$ with 3 D compared with only $65 \%( \pm 18 \%)$ in Limit-2D plan, again the difference was statistically significant $(p=0.01)$. The traditional use of 1 direct field for the SCV and calculation at depth $3 \mathrm{~cm}$ simply underestimates the depth of SCV and axillary apex lymph nodes specially in patients with high Body Mass Index (BMI) or big separation hence the poor coverage while in $3 \mathrm{D}$ posterior field was allowed with small weighting. With $3 \mathrm{D}$ plans SCV V107\%, V112\% and D-max were all lower than 2D plans however did not reach statistical significance.

The use of MIS in 3D plans allowed for marked elimination of junctional hot spots, $107 \%( \pm 4 \%)$ compared to $120 \%( \pm 9 \%)$ in 2 D plans ( $p=0.04)$.

In our study, the target coverage was better than that reported by Z. Falahatpouret et al., [12] (breast V95\% was 74\% with 2D and 81\% with 3D plans) and inferior to Hans Paul van der Laan et al. [13] and Rudra et al. [5] whose results were similar (breast V95\% was $95 \%$ with $2 \mathrm{D}$ and $99 \%$ with 3D plans). This inferior coverage with Limit-2D in our study can be explained by missing the medial and lateral Parts of the Breast (PTV) when the posterior border of the field was not allowed to include more than $2 \mathrm{~cm}$ of ipsilateral lung. When 2D plan was modified to cover breast PTV at central slice, Mod-2D, the coverage improved to $84 \%( \pm 10 \%)$ but on the expense of more dose to OAR. SCV V90\% in our study (65\% in 2D and $90 \%$ in 3D) was slightly inferior to those reported by Rudra et 
al., [5] (78\% for 2D and 93.6\% in 3D). Different patients' average BMI or separation is a possible explanation.

In $2 \mathrm{D}$ plan the mean dose received in the junction area was $(120 \% \pm 9 \%)$ of the prescribed dose compared to $(107 \% \pm 4 \%)$ in $3 \mathrm{D}$ plans. This was comparable with Assaoui, F. et al. [14].

\subsection{OAR Sparing}

\subsubsection{The Heart in Case of Left Sided Breast}

In our study the average value of mean heart dose in case of left sided breast was $491 \mathrm{cGy}$ in 3D plans compared to $782 \mathrm{cGy}$ in Mod-2D plans and the difference was significant statistically $(p=0.025)$. Heart V10 and V20 were also better with 3D plan however NS. Although Limit-2D plans had statistically NS lower mean heart dose (333 cGy), this plan failed to cover the target volume properly.

This 3D mean heart dose is acceptable by the RTOG 1005 guidelines for left side breast and better than that reported by Rudra et al., (640 cGy) [5] and Hans Paul van der Laan et al., (550 cGy) 10]. Likewise the V10 and V20 in our study (10\% and 7\%) were better than reported by Rudra et al. (17.5\% and $8 \%)$ This can be explained by the lower but still acceptable breast V95\% in our study (95.3\% compared to $99.2 \%$ in Rudra et al., study).

\subsubsection{The Ipsilateral Lung}

In our study Ipsilateral lung V20 was $26 \%$ in 3D plans compared to $32 \%$ in Mod-2D plans and there was trend towards statistical significance $(p=0.07)$. Although Limit-2D plans had statistically NS lower ipsilateral lung V20 (19\%), this plan failed to cover the target volume properly.

This 3D Ipsilateral lung V20 is comparable with QUANTEC [15] guideline which recommended that V20 must deliver $(\leq 30 \%)$ and higher than accepted by the RTOG 1005 guidelines $(\leq 20 \%)$ however it is better than that reported by Rudra et al., (44\%) [5]. This again can be explained by the lower but still acceptable breast V95\% in our study (95.3\% compared to $99.2 \%$ in Rudra et al., study).

Both Hans Paul van der Laan et al., [13], and Falahatpour et al., [12] were reporting the Ipsilateral lung V30 (3.5\% and 9\% respectively in 3D plans).

Further attempt to lower the dose to OAR was made in this study by lowering the breast PTV coverage to V90\% $\geq 90 \%$ instead of V95\% > 95 (still accepted by RTOG 1005 guidelines), the Ipsilateral lung V20 dropped to 17\% (compared to $26 \%$ with p value of 0.026 ) and mean heart dose dropped to $298 \mathrm{cGy}$ (compared to $491 \mathrm{cGy}$ with $\mathrm{p}$ value 0.09 ).

\section{Limitations of the Study}

As with similar type of studies, the clinical effect of the dosimetric findings cannot be evaluated. Those patients need to be followed up clinically for an appropriate time to assess for the difference in loco-regional control and late toxicity.

\section{Conclusions}

This study demonstrated that application of 3D plan using MIT improves cov- 
erage of intact breast and SCV PTVs with elimination of hot spot at the junctional area if compared with clinically-based Limit-2Dplans however with non statistically significant higher dose to OAR.

When comparing 3D plans with central slice PTV-based 2D (Mod-2D) plans, $3 \mathrm{D}$ plans not only had better target coverage but also better sparing of OAR, the latter was statistically significant.

\section{References}

[1] Mokhtar, N., Gouda, I. and Adel, I. (2007) Cancer Pathology Registry 2003-2004 and Time Trend Analysis Book. Cairo Press, Cairo.

[2] Madu, C.N., Quint, D.J., Normolleet, D.P., et al. (2001) Definition of the Supraclavicular and Infraclavicular Nodes: Implications for Three Dimensional CT-Based Conformal Radiation Therapy. Radiology, 221, 333-339. https://doi.org/10.1148/radiol.2212010247

[3] Pignol, J.P., Olivotto, I., Rakovitch, E., et al. (2008) A Multicenter Randomized Trial of Breast Intensity-Modulated Radiation Therapy to Reduce Acute Radiation Dermatitis. Journal of Clinical Oncology, 26, 2085-2092.

https://doi.org/10.1200/JCO.2007.15.2488

[4] Donovan, E., Bleakley, N., Denholm, E., et al. (2007) Randomized Trial of Standard 2D Radiotherapy (RT) versus Intensity Modulated Radiotherapy (IMRT) in Patients Prescribed Breast Radiotherapy. Radiotherapy \& Oncology, 82, 254-264. https://doi.org/10.1016/j.radonc.2006.12.008

[5] Rudra, S., Al-Hallaq, H., Feng, C., et al. (2014) Effect of RTOG Breast/Chest Wall Guidelines on Dose-Volume Histogram Parameters. Journal of Applied Clinical Medical Physics, 15, 4547. https://doi.org/10.1120/jacmp.v15i2.4547

[6] Haciislamoglu, E., Colak, F., Canyilmaz, E., et al. (2016) The Choice of Multi-Beam IMRT for Whole Breast Radiotherapy in Early-Stage Right Breast Cancer. Springerplus, 5, 688. https://doi.org/10.1186/s40064-016-2314-2

[7] Radiation Therapy Oncology Group (RTOG) (2013) Breast Cancer Atlas for Radiation Therapy Planning: Consensus Definitions. http://www.rtog.org/LinkClick.aspx?fileticket=vzJFhPaBipE\%3d\&tabid=236

[8] McNair, H.A. (Royal Marsden NHS Trust Sutton) (2011) Practical Issues of Planning and Delivery: Breast Cancer.

[9] Svensson, G.K., Bjarngard, B.E. and Larsen, R.D. (1980) A Modified Three-Field Technique for Breast Treatment. International Journal of Radiation, Oncology, Biology and Physics, 6, 689-694. https://doi.org/10.1016/0360-3016(80)90224-2

[10] ICRU (International Commission on Radiation United and Measurements) (1993) Prescribing, Recording and Reporting Photon Beam Therapy. ICRU Report 50, ICRU, Bethesda.

[11] Nrg Oncology Rtog 1005 (2014) A Phase III Trial of Accelerated Whole Breast Irradiation with Hypo Fractionation plus Concurrent Boost versus Standard Whole Breast Irradiation plus Sequential Boost for Early-Stage Breast Cancer. https://www.rtog.org/clinicaltrials/protocoltable/studydetails.aspx?action=openFile

[12] Falahatpour, Z., Aghamiri, S.M.R. and Anbiaee, R. (2011) External Radiotherapy of Intact Breast: A Comparison between 2D (Single CT-Slice) and 3D (Full CT-Slices) Plans. Iranian Journal of Radiation Research, 9, 121-125.

[13] van der Laan, H.P., Dolsma, W.V., Maduro, J.H., Korevaar, E.W. and Langendijk, J.A. (2008) Dosimetric Consequences of the Shift towards Computed Tomography 
Guided Target Definition and Planning for Breast Conserving Radiotherapy. Radiation Oncology, 3, 6. https://doi.org/10.1186/1748-717X-3-6

[14] Assaoui, F., Toulba, A., Nouh, M., Lkhouyaali, S., Bensouda, Y., Kebdani, T. and Benjaafar, N. (2012) Mono-Iso-Centeric Technique in the Breast Cancer and Organ at Risk Tolerance. Journal of Nuclear Medicine and Radiation Therapy, S2, 2.

[15] Soren, M., et al. (2010) Quantitative Analyses of Normal Tissue Effects in the Clinic (QUANTEC): An Introduction to the Scientific Issues. International Journal of Radiation, Oncology, Biology and Physics, 76, S3-S9.

https://doi.org/10.1016/j.ijrobp.2009.09.040

\section{Scientific Research Publishing}

Submit or recommend next manuscript to SCIRP and we will provide best service for you:

Accepting pre-submission inquiries through Email, Facebook, LinkedIn, Twitter, etc. A wide selection of journals (inclusive of 9 subjects, more than 200 journals)

Providing 24-hour high-quality service

User-friendly online submission system

Fair and swift peer-review system

Efficient typesetting and proofreading procedure

Display of the result of downloads and visits, as well as the number of cited articles Maximum dissemination of your research work

Submit your manuscript at: http://papersubmission.scirp.org/

Or contact jct@scirp.org 